\title{
MỘT SỐ GIẢI PHÁP NÂNG CAO CHÂT LƯợNG ĐÀO TẠO THEO TỈN CHỈ \\ TẠI TRƯỜnG ĐẠI HỌC TÂN TRÀO
}

\section{Some solutions to improve quality credit-based training at Tan Trao university}

Ngày nhận bài: 03/10/2016; ngày phản biện: 22/2/2017; ngày duyệt đăng: 22/3/2017

Lê Thị Thu Hà*

\section{TÓM TẮT}

Chủ trương chuyển đổi phương thức đào tạo theo học chế tín chỉ đã được Bộ Giáo dục và Đào tạo triển khai từ năm học 2006-2007. Tuy nhiên, đến nay vấn đề đào tạo theo tín chỉ vẫn còn nhiều điều cần phải trao đổi vì những khó khăn, vướng mắc mà các trường đang gặp phải. Trường Đại học Tân Trào tỉnh Tuyên Quang đã thực hiện đào tạo theo tín chỉ bắt đầu từ năm học 20142015. Qua gần 3 năm triển khai, đào tạo theo tín chỉ đã bước đầu thu được những kết quả nhất định, tuy nhiên cũng gặp không ít những khó khăn, thách thức đòi hỏi nhà trường cần phải có những giải pháp đồng bộ từ công tác quản lý đến việc điều chỉnh khung chương trình, đề cương chi tiết học phần, đổi mới cách thức dạy và học của giảng viên và sinh viên...

Tù̀ khóa: Tín chỉ; đào tạo; chất lượng đào tạo; đào tạo tín chỉ; tụ hoc; giáo dục đại học.

\section{ABSTRACT}

Policy converts training procedure into credit training has been deployed by the Ministry of Education and Training from the 2006-2007 school year. However, up to this time there are many things need to be discussed the credit training's problem because of its difficulties in which the schools are catching. Tân Trào University, Tuyên Quang province, has been realized credit training since 2014-2015 school year. Nearly 3 years of deployment, training credits start of realize has obtained some determinate results. However, there are also many difficulties and challenges required. Schools need to have consistent solutions from management to adjustment of the curriculum framework, draft subject platform details. Innovation in teaching and learning of faculty and students ...

Key words: Credits; training; education quality; training credits; self-learning; higher education

\section{Đặt vấn đề}

Đào tạo theo học chế tín chỉ là 1 trong 7 bước đi quan trọng trong lộ trình đổi mới giáo dục đại học giai đoạn 2006-2020. Nghị quyết 29/NQ-TW ngày 04 tháng 11 năm 2013 của Ban chấp hành Trung ương "Về đổi mới căn bản, toàn diện Giáo dục và Đào tạo, đáp ứng yêu cầu công nghiệp hóa, hiện đại hóa trong điều kiện kinh tế thị trường định hướng xã hội chủ nghĩa và hội nhập quốc tế" đã chỉ rõ "Tiếp tục đổi mới mạnh mẽ phương pháp dạy và học theo hướng hiện đại; phát huy tính tích cực, chủ động, sáng tạo và vận dụng kiến thức, kỹ năng của người học; khắc phục lối truyền thụ áp đặt một chiều, ghi nhớ máy móc. Tập trung dạy cách học, cách nghĩ, khuyến khích tự học, tạo cơ sở để người học tự cập nhật và đổi mới tri thức, kỹ năng, phát triển năng lực. Chuyển từ học chủ yếu trên lớp sang tổ chức hình thức học tập đa dạng, chú ý các hoạt động xã hội, ngoại khóa, nghiên cứu khoa học. Đẩy mạnh ứng dụng công nghệ thông tin và truyền thông 
trong dạy và học" và phải "Thực hiện đào tạo theo tín chỉ". Theo tinh thần chỉ đạo đó, từ năm học 2014-2015, trường Đại học Tân Trào đã thực hiện việc chuyển đổi phương thức đào tạo từ niên chế sang tín chỉ trong toàn bộ hệ đại học và cao đẳng chính quy. Trong khuôn khổ bài viết này, tác giả chỉ muốn nêu lên những khó khăn, vướng mắc trong việc thực hiện đào tạo theo tín chỉ tại Trường đại học Tân Trào dưới góc nhìn cá nhân và đề xuất một số giải pháp nâng cao hiệu quả hình thức đào tạo này.

\section{Một số khó khăn trong đào tạo theo hệ} thống tín chỉ tại Trường Đại học Tân Trào

Qua gần ba năm thực hiện, bên cạnh những kết quả đạt được, đào tạo theo hệ thống tín chỉ tại trường Đại học Tân Trào vẫn còn một số khó khăn, vướng mắc.

\subsection{Công tác điều hành, quản lý}

Nếu như trong đào tạo niên chế, sinh viên học theo một kế hoạch chung do nhà trường sắp xếp (theo biên chế năm học, thời khóa biểu từng kỳ học) thì trong đào tạo tín chỉ, mỗi sinh viên có kế hoạch học tập riêng. Nhiều sinh viên vẫn quen với tư duy, cách thức làm việc cũ, có tư tưởng dựa dẫm vào đội ngũ cán sự lớp trong việc triển khai các nhiệm vụ của nhà trường, vì vậy nhiều em không biết kế hoạch học tập thế nào, chương trình đào tạo ra sao, không biết cách đăng ký học phần, việc tính điểm, việc học cải thiện điểm, việc cảnh báo kết quả học tập...Việc tổ chức sinh hoạt lớp, tham gia các hoạt động đoàn thể cũng có nhiều thay đổi do mỗi sinh viên có lịch học tập riêng. Kế hoạch học tập cá nhân (đăng ký học phần, lựa chọn giảng viên, điều chỉnh kế hoạch học tập, học cải thiện điểm...) được thực hiện chủ yếu thông qua phần mềm quản lý đào tạo... Tất cả những thay đổi này làm cho công tác quản lý, điều hành gặp không ít khó khăn.
Thực tế, trường đại học Tân Trào mới tuyển sinh được ba khóa hệ đại học chính quy. Do sự thay đổi cách thức thi tuyển sinh hệ đại học, cao đẳng của Bộ Giáo dục và Đào tạo trong những năm gần đây mà trường cũng như một số đại học địa phương khác gặp rất nhiều khó khăn trong việc tuyển sinh. Ở một số ngành hệ đại học ngoài sư phạm và các ngành hệ cao đẳng số lượng sinh viên nhập học thấp (cá biệt 1 số ngành chỉ có trên dưới 10 $\mathrm{SV} /$ ngành), vì vậy, việc triển khai đăng ký học phần, lựa chọn giảng viên rất khó thực hiện.

\subsection{Chương trình đào tạo}

Ngay sau khi thực hiện việc chuyển đổi hình thức đào tạo, trường Đại học Tân Trào đã thành lập Ban xây dựng chương trình đào tạo bao gồm những giảng viên trình độ cao, có nhiều kinh nghiệm trong công tác giảng dạy và quản lý chuyên môn. Nhà trường cũng đã tổ chức cho giảng viên trong ban đi học tập kinh nghiệm ở các trường đại học có bề dày về đào tạo tín chỉ. Chương trình đào tạo được xây dựng trên cơ sở khung chương trình của Bộ Giáo dục và Đào tạo gồm: Khối kiến thức giáo dục đại học và khối kiến thức giáo dục chuyên nghiệp (kiến thức cơ sở ngành, kiến thức chuyên ngành và kiến thức bổ trợ) đáp ứng nhu cầu đào tạo về kiến thức, kỹ năng trình độ cao đẳng, đại học. Chương trình thường xuyên được đánh giá, bổ sung, điều chỉnh, cập nhật mới trên cơ sở tham khảo những chương trình đào tạo tiên tiến của các trường đại học. Tuy nhiên, chương trình đào tạo vẫn còn nhiều bất cập, việc điều chỉnh, bổ sung chương trình đào tạo chưa có sự tham khảo các chương trình tiên tiến quốc tế, chưa tham khảo được ý kiến các nhà tuyển dụng, người học sau tốt nghiệp, các tổ chức liên quan nhằm đáp ứng nhu cầu nguồn nhân lực phát triển kinh tế-xã hội. Mặt khác, việc đánh giá chương trình đào tạo chỉ thực sự có hiệu quả sau khi kết thúc đào tạo ít nhất một khóa (nhà trường mới đào tạo hệ đại 
học được 3 năm, chưa có lớp sinh viên đại học nào ra trường). Vì vậy, việc khảo sát chương trình đào tạo cũ, xây dựng chương trình mới của nhà trường đã được triển khai thực hiện nhưng thực chất chưa đi vào chiều sâu.

\section{3. Đội ngũ cố vấn học tập}

Hiện tại nhà trường có 218 giảng viên, trong đó 36 giảng viên được giao nhiệm vụ cố vấn học tập. Công việc cố vấn học tập thường giao cho các giảng viên trẻ, họ có sự nhiệt tình, có trình độ cao, tuy nhiên chưa có nhiều kinh nghiệm trong giảng dạy cũng như trong công tác giáo dục sinh viên, chưa phải là chuyên gia trong việc tư vấn các vấn đề liên quan đến học tập, rèn luyện, nghiên cứu khoa học. Mặt khác một cố vấn học tập phải phụ trách rất nhiều sinh viên (36 cố vấn học tập/1267 sinh viên). Vì vậy, chất lượng công tác cố vấn học tập chưa cao.

\section{4. Ý thức tự học của sinh viên}

Bản chất của việc học theo phương thức tín chỉ là sinh viên tự học, tự nghiên cứu dưới sự hướng dẫn, giúp đỡ của giảng viên. Tuy nhiên, hầu hết các em chưa xây dựng được phương pháp học tập phù hợp, chưa có thói quen coi những giờ tự học, những giờ chuẩn bị bài là một phần của môn học. Quan sát trong các giờ học, chúng tôi thấy rằng khi giao bài tập về nhà cho sinh viên tự nghiên cứu thì rất nhiều em không làm hoặc làm sơ sài, làm cho có. Căn cứ sổ ghi chép việc mượn sách thư viện và tần suất số lần sinh viên lên phòng đọc tự học thấy rằng rất ít sinh viên mượn tài liệu, đọc sách tại như viện. Năm học 2016-2017, chỉ có 11 sinh viên tham gia nghiên cứu khoa học. Thực tế này nảy sinh vấn đề nếu sinh viên không đổi mới phương pháp học tập, không tăng cường công tác tự học, tự nghiên cứu thì có khả năng sẽ xảy ra nguy cơ đào tạo theo tín chỉ chất lượng kém hơn đào tạo theo niên chế.

\subsection{Cơ sở vật chất, trang thiết bị dạy học}

Trường Đại học Tân Trào có 56 phòng học lý thuyết, 10 phòng học chức năng đảm bảo đầy đủ ánh sáng, hệ thống quạt điện, bàn ghế, trong đó một số phòng học được trang bị hệ thống âm ly, loa, máy chiếu projeter...Thư viện có diện tích $358 \mathrm{~m}^{2}$, bao gồm: kho sách tham khảo, kho sách giáo trình, kho sách nghiệp vụ và phòng đọc. Kho sách của Thư viện được sắp xếp và phục vụ bạn đọc theo mô hình thư viện truyền thống bao gồm 4927 đầu sách với 143094 bản. Thư viện, phòng đọc được trang bị hệ thống máy tính kết nối mạng nội bộ và Internet, có hệ thống máy chủ, sử dụng đường truyền FTTH nhanh, mạnh phục vụ nhu cầu dạy và học của giảng viên và sinh viên. Tuy nhiên, trường chưa có nhà thư viện riêng biệt, nhiều phòng học, phòng thực hành diện tích nhỏ $\left(50 \mathrm{~m}^{2}\right)$, chưa được lắp đặt các phương tiện kỹ thuật dạy học, sách, giáo trình, tài liệu tham khảo còn thiếu, chưa đáp ứng được nhu cầu nguồn tài liệu phục vụ cho công tác dạy - học.

Từ thực trạng trên cho thấy để phương thức đào tạo theo học chế tín chỉ thực sự đi vào bản chất và hoạt động có hiệu quả thì còn nhiều khó khăn vướng mắc cần tháo gỡ.

2. Một số giải pháp nâng cao chất lượng đào tạo theo tín chỉ tại trường Đại học Tân Trào

Tinh thần cốt lõi của việc chuyển đổi từ phương thức đào tạo niên chế sang học chế tín chỉ là: thầy phải thay đổi cách dạy, trò phải thay đổi cách học và lãnh đạo phải thay đổi cách quản lý. Chỉ khi nào đạt được sự đồng bộ đó chúng ta mới hy vọng có được một sự hoàn thiện trong tổ chức đào tạo theo học chế tín chỉ. Vì vậy, để quá trình triển khai đào tạo theo học chế tín chỉ đi vào thực chất nhà trường cần tiến hành các giải pháp sau đây: 
2.1. Cần thay đổi nhận thức của cán bộ quản lý, giảng viên và sinh viên: xác định việc chuyển đổi sang phương thức đào tạo tín chỉ là việc phải làm, nên làm trong lộ trình đổi mới giáo dục đại học, từ đó xây dựng quyết tâm chung của toàn thể cán bộ, giảng viên, sinh viên trong việc thực hiện nghiêm túc, có hiệu quả mọi nhiệm vụ được giao. Đảm bảo việc triển khai thực hiện đồng bộ từ các đơn vị tham mưu như phòng Đào tạo, phòng Khảo thí - Đảm bảo chất lượng, phòng Quản lý sinh viên, ban xây dựng chương trình đào tạo... đến các đơn vị khoa chuyên môn, bộ môn sao cho phù hợp chức năng, nhiệm vụ của từng đơn vị, cá nhân. Làm cho mỗi cá nhân cán bộ, giảng viên, sinh viên đều hiểu rõ nội dung các quy chế, quy định của Bộ Giáo dục và Đào tạo, của nhà trường về công tác đào tạo theo tín chỉ: từ việc xây dựng kế hoạch đào tạo, đổi mới chương trình đào tạo, việc đăng ký học phần, lựa chọn giảng viên, cách tính điểm, đăng ký học cải thiện điểm, việc cảnh báo kết quả học tập... đến vai trò của cố vấn học tập, kế hoạch hoạt động của các tổ chức Đoàn, Hội trong nhà trường...

\section{2. Đổi mới hệ thống điều hành, quản lí} đào tạo theo hướng mềm dẻo, linh hoạt: Quản lý đào tạo bằng phần mềm quản lý, từ những thông tin cá nhân đến toàn bộ kết quả học tập, rèn luyện của sinh viên trong suốt quá trình học tập và phải có biện pháp quản lý dữ liệu phù hợp tránh sự xâm nhập hệ thống của các đối tượng khác (sau mỗi kỳ thi toàn bộ dữ liệu kết quả học tập của sinh viên được ghi vào đĩa $\mathrm{CD}$ để lưu trữ).

2.3. Xây dựng chương trình đào tạo ổn định, công khai hoá từ nội dung cho đến lịch trình giảng dạy, từ các điều kiện tiên quyết của từng học phần, cho đến lịch học, lịch thi... Chương trình đào tạo phải đảm bảo tính liên thông rộng, phần kiến thức tự chọn đủ lớn tạo cơ hội cho sinh viên dễ dàng chuyển đổi ngành nghề và tích luỹ kiến thức để sớm nhận được văn bằng ở các chuyên ngành thứ hai, thứ ba. Chương trình phải được đánh giá và thường xuyên bổ sung, cải tiến, cập nhật những nội dung mới. Chương trình cần có ý kiến phản hồi của người học sau tốt nghiệp, các nhà tuyển dụng và các tổ chức xã hội nghề nghiệp.

2.4. Nâng cao chất lượng đội ngũ giảng viên, cố vấn học tập: Xây dựng lực lượng giảng viên cơ hữu đủ về số lượng, đáp ứng yêu cầu về chất lượng để đảm bảo các học phần được tổ chức giảng dạy liên tục trong tất cả các học kỳ, tạo cơ hội cho sinh viên được lựa chọn tiến độ học tập. Đội ngũ cố vấn học tập phải là những người thực sự tâm huyết với nghề, có tinh thần trách nhiệm, có trình độ cao, có kinh nghiệm trong công tác giáo dục, giảng dạy, thường xuyên được tập huấn, bồi dưỡng về nghiệp vụ, chuyên môn, đồng thời cố vấn học tập phải là chuyên gia trong việc tư vấn các vấn đề liên quan đến học tập, rèn luyện, nghiên cứu khoa học... của sinh viên. Có những chính sách hỗ trợ phù hợp về vật chất cho đội ngũ giảng viên trình độ cao, tạo điều kiện cho họ được học tập, bồi dưỡng nâng cao trình độ về mọi mặt đáp ứng yêu cầu khi có sự thay đổi.

2.5. Nâng cao ý thức tự học, tự nghiên của sinh viên: Để thích ứng với việc đổi mới phương pháp giảng dạy theo hướng tác động đến người học một cách tích cực và tăng cường độ làm việc của người học thì bản thân người học phải tự giác, tích cực tự học, tự nghiên cứu: hoạt động dạy của giảng viên là hướng dẫn và giao nhiệm vụ cho sinh viên tự tìm kiếm kiến thức ở ngoài lớp học (ở nhà, trong thư viện, trong phòng thí nghiệm...); giải thích những vấn đề mà sinh viên gặp khó khăn khi tự nghiên cứu; hướng dẫn thảo luận những vấn đề trong tài liệu mà sinh viên đã đọc; giới thiệu các vấn đề học thuật đang được tranh luận; hướng dẫn SV những điều cần chú ý 
khi làm thí nghiệm, thực hành, khi đi thực tế, khi tra cứu tài liệu trên mạng, thư viện...

2.6. Đổi mới phương pháp kiểm tra đánh giá theo hướng đánh giá quá trình, đánh giá năng lực người học theo chuẩn kiến thức, kỹ năng và phải đảm bảo tính chính xác, khách quan: Sử dụng nhiều phương pháp, hình thức kiểm tra, đánh giá; đánh giá sinh viên thông qua các hoạt động trên lớp (số buổi có mặt, theo dõi bài giảng, thảo luận), tự học ở nhà (qua nội dung phát biểu thảo luận trên lớp, thời gian và chất lượng hoàn thành bài tập ở nhà do giảng viên giao), làm việc trong phòng thí nghiệm, đi thực tế và đánh giá qua bài thi kết thúc môn học...

2.7. Tăng cường cơ sở vật chất và thiết bị dạy học: Xây dựng trung tâm Thông tin Thư viện hiện đại, kết nối với các trung tâm học liệu uy tín đáp ứng nhanh nhất, đầy đủ nhất nhu cầu tra cứu tài liệu dạy-học của giảng viên và sinh viên, chuyển sang mô hình thư viện điện tử, mua các tài liệu online, tận dụng các tài liệu $C D-R O M$ và tận dụng các kho mở của $\mathrm{MIT}$ và $\mathrm{IBM}$. Bổ sung sách, giáo trình và tài liệu tham khảo cho các môn học, thường xuyên cập nhật các tài liệu mới. Tăng cường đầu tư mở rộng cơ sở đào tạo, các phòng học chức năng với các trang thiết bị dạy học hiện đại, đủ chuẩn, các phòng thí nghiệm, thực hành đáp ứng yêu cầu. Xây dựng tủ sách chuyên môn tại các khoa, bộ môn. Định kỳ lấy ý kiến phản hồi của sinh viên và giảng viên nhằm không ngừng cải tiến hoạt động phục vụ đáp ứng yêu cầu công tác dạy và học.

2.8. Xây dựng Sổ tay sinh viên (phát cho sinh viên đầu khóa học): giới thiệu về trường và những yêu cầu mà sinh viên phải thực hiện: tổng số tín chỉ phải tích lũy, tổng số tín chỉ tối thiểu phải tích lũy từng năm, số tín chỉ tối thiểu, tối đa được đăng ký học trong từng học kỳ; thời gian và địa điểm có thể gặp cố vấn; cách thức kiểm tra - đánh giá, cách xếp hạng kết quả môn học và cách tính điểm trung bình chung, việc học cải thiện điểm, cảnh báo kết quả học tập, bảo lưu kết quả học tập, điều kiện xét tốt nghiệp và hồ sơ xét tốt nghiệp...

\section{Kết luận}

Có thể khẳng định, học chế tín chỉ là phương thức đào tạo rất mềm dẻo, linh hoạt, với nhiều ưu thế. Tuy nhiên, để đào tạo tín chỉ đi vào thực chất, phát huy được hiệu quả đòi hỏi các trường cần có sự chuẩn bị chu đáo về mọi mặt, đặc biệt là sự thay đổi về tư duy quản lý, đổi mới cách thức dạy và học. Thực hiện chuyển đổi phương thức đào tạo từ niên chế sang tín chỉ tại trường Đại học Tân Trào tuy còn gặp nhiều khó khăn (về phương thức lãnh đạo, quản lý, chương trình đào tạo, cách thức dạy và học, cơ sở vật chất, trang thiết bị dạy học...) nhưng đã thu được những kết quả nhất định. Điều này đã và đang khẳng định hướng đi đúng đắn trong lộ trình đổi mới giáo dục của một ngôi trường đại học non trẻ trên quê hương cách mạng - Trường Đại học Tân Trào. 


\section{TÀI LIỆU THAM KHẢO}

1. Trần Thanh Ái (2010), "Đào tạo theo hệ thống tín chỉ - Các nguyên lí, thực trạng và giải pháp”, Kỷ yếu hội thảo khoa học toàn quốc Đổi mới phương pháp giảng dạy đại học theo tín chỉ, Chuyên san của Tạp chí Đại học Sài Gòn;

2. Bộ Giáo dục và Đào tạo (2007), Quy chế đào tạo đại học và cao đẳng hệ chính quy theo hệ thống tín chỉ (Ban hành kèm theo Quyết định số 43/2007/QĐ-BGDĐT ngày 15 tháng 8 năm 2007 của Bộ trưởng Bộ Giáo dục và Đào tạo);

3. Đào Ngọc Cảnh, Trịnh Duy Oánh (2012), "Một số vấn đề về đào tạo theo học chế tín chỉ”, Tạp chí Đại học Sài Gòn;

4. Diệp Ngọc Dũng (2010), "Một số tồn tại trong quá trình chuyển đổi sang đào tạo theo hệ thống tín chỉ”, Kỷ yếu hội nghị Tổng kết, đánh giá công tác đào tạo tín chỉ, Trường Đại học Cần Thơ;

5. Trường Đại học Tân Trào, 2016, Quy chế đào tạo đại học, cao đẳng theo hệ thống tín chỉ (Ban hành kèm theo Quyết định số 1838/QĐ-ĐHTT ngày 28 tháng 9 năm 2015 của Hiệu trưởng Truòng Đại học Tân Trào);

6. Lâm Quang Thiệp (2010), "Về phương pháp dạy, học và đánh giá kết quả học tập trong hệ thống tín chỉ”, Kì yếu hội thảo khoa học toàn quốc Đổi mới phương pháp giảng dạy đại học theo tín chi, Chuyên san của Tạp chí Đại học Sài Gòn. 